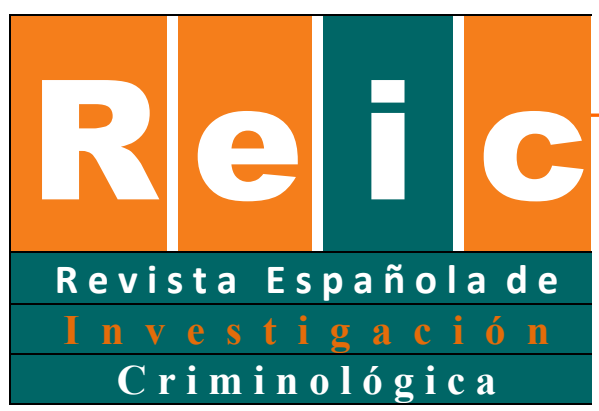

Tamarit, Guardiola, Hernández-Hidalgo \& Padró-Solanet

\title{
La victimización sexual de menores de edad: un estudio de sentencias
}

\section{Sexual victimization of minors: a study on sentencing}

Recibido el 12 julio 2014/Publicado el 19 noviembre 2014

Josep M. Tamarit

Universidad de Lleida y Universidad Oberta de Cataluña

María Jesús Guardiola

Universidad Autónoma de Barcelona

Patricia Hernández-Hidalgo

Universidad Oberta de Cataluña

Albert Padró-Solanet ${ }^{1}$

Universidad Oberta de Cataluña

\section{RESUMEN}

El artículo, tras una revisión de las publicaciones existentes en el ámbito internacional sobre la respuesta del sistema de justicia penal a la victimización sexual de menores de edad, presenta los resultados de un estudio cuantitativo de sentencias judiciales dictadas por diversas Audiencias Provinciales españolas en 2011 y 2012, en el que se examina en

\footnotetext{
1 Autora de correspondencia: Maria Jesús Guardiola Lago. Universidad Autónoma de Barcelona. Departamento de Ciencia Política y Derecho Público. Área de Derecho penal. Edificio B- Campus Bellaterra, 08193, Bellaterra (Cerdanyola del Vallès) Spain. mariajesus.guardiola@uab.cat
} 
qué modo diversas variables referidas a la víctima, al ofensor y a las características del hecho inciden en las decisiones adoptadas por los Tribunales. El estudio, basado en 420 casos, establece la relevancia de aspectos como la relación previa entre autor y víctima o la edad de ésta y valida la declaración anticipada como medio probatorio eficaz.

Palabras clave: victimización, abuso sexual a menores, sistema de justicia penal.

\begin{abstract}
After reviewing the literature on how the criminal justice system deals with sexual victimization of children, the article presents the results of a quantitative study of judgments rendered by several Spanish courts in 2011 and 2012. We evaluated the influence of different variables related to the victim, the offender and the offence on the courts' decisions. The study, based on 420 cases, proves that previous relationship between victim and perpetrator and victims' age are relevant predictors of judicial decisions. The results also validate the early statement of victims in the criminal proceeding as effective evidence.
\end{abstract}

Key words: victimization, child sexual abuse, criminal justice system.

\title{
1. Introducción
}

El estudio empírico sobre el modo en que el sistema de justicia penal responde a los casos denunciados de delitos sexuales contra menores de edad se encuentra todavía en una fase muy incipiente, especialmente en Europa, dado que la práctica totalidad de estudios publicados han sido realizados en los EUA. Nuestra aportación al tema se centra en un análisis cuantitativo de sentencias judiciales dictadas en España en los años 2011 y 2012 y constituye una parte de un proyecto de investigación más amplio, en el que también serán examinados aspectos relativos a fases anteriores a la sentencia. El presente estudio incide en un aspecto fundamental de la intervención del sistema de justicia penal, como son las decisiones adoptadas por el tribunal sentenciador. Para ello se pretende evaluar estas decisiones en los delitos sexuales contra menores de edad, al objeto de conocer los factores que influyen en ellas. A continuación se va a presentar el resultado de una exhaustiva revisión de las publicaciones existentes a nivel internacional. Posteriormente se expondrán los objetivos, la metodología y los resultados de nuestro estudio, seguidos de una discusión de los aspectos más relevantes 
y las conclusiones finales orientadas a establecer pautas de actuación en el ámbito de la prevención, política criminal y futura investigación.

\section{Estado de la cuestión}

\subsection{Investigación sobre análisis de sentencias}

$\mathrm{Si}$ bien es cierto que a nivel internacional existe un importante número de investigaciones sobre análisis de sentencias, los resultados obtenidos son controvertidos y los autores insisten en la necesidad de mayor investigación en este ámbito. La disparidad constituye una de las principales preocupaciones de los investigadores, por lo que han tratado de averiguar cuáles son los factores relevantes que pueden influir en las decisiones judiciales sobre condenar o no al acusado, si la pena a imponer es la de prisión o una pena menos aflictiva y cuál es la determinación temporal de la misma.

Los factores que agravan o atenúan la pena pueden ser de carácter legal, en tanto que la ley prevé de forma explícita las circunstancias, tales como la gravedad de la ofensa, la existencia de condenas anteriores, las consecuencias del delito o la reparación del daño, así como sus efectos sobre la determinación de la pena. Sin embargo, los factores que pueden influir en estas decisiones pueden ser también de naturaleza extralegal, ya sean tenidos en cuenta conscientemente o no por el tribunal. Algunos autores sugieren que el interés de la criminología por los factores extralegales como la clase social, la etnia y el género es una contribución de los teóricos del conflicto, quienes hicieron hincapié en la interrelación entre la justicia penal y los sistemas de estratificación social (Black, 1976; Kingsnorth, et al., 1998). Esta perspectiva ha refutado la teoría del consenso, que parte de la presunción de que el proceso de toma de decisiones es impulsado únicamente por variables legalmente reconocidas. El enfoque feminista ha sido una de las versiones de la perspectiva del conflicto, mediante el análisis del papel del género.

La investigación empírica puede ayudar a revelar cuáles son estos factores y en qué medida son capaces de influir en el castigo impuesto efectivamente al infractor, contribuyendo así a una revisión crítica de un momento tan trascendente en la toma de decisiones judiciales. Cuando estos factores son evaluados de forma explícita por el Tribunal y fundamentados en principios legales o constitucionales o en valores sociales, 
la investigación puede centrarse en el análisis de la motivación de las resoluciones judiciales, básicamente a través de metodología cualitativa. No obstante, tienen un particular interés los factores no explicitados pero con un impacto real en la toma de decisiones judiciales, que pueden estar relacionados con problemas de prueba o atribuirse a la cultura judicial o a preconcepciones o estereotipos sociales sobre el autor o sobre la víctima, relacionados con el sexo, la etnia, la edad o el estilo de vida, entre otros. La investigación cuantitativa puede aportarnos información útil para medir el impacto real de dichas variables.

En los países anglosajones existe un importante número de estudios que han examinado la toma de decisiones judiciales. La fase relativa a la sentencia ha recibido especial atención, ya que los datos contenidos en los juicios son registrados y son más fácilmente accesibles a los investigadores, en comparación con la información sobre otras decisiones judiciales dictadas en otras fases del proceso penal. Algunos estudios diferencian los factores analizados en función de tres categorías básicas: a) Factores relacionados con el delito; b) Factores relacionados con el delincuente; y c) Factores relacionados con la víctima. La validez de esta clasificación no es evidente, dado que la atribución de variables tales como la relación entre la víctima y el ofensor puede ser problemática, pero es aceptada por muchos autores. La mayor parte de la investigación se ha centrado en el primero y el segundo grupo de variables, recibiendo menos atención las relativas a las características de la víctima. Asimismo los delitos sexuales no son de los más estudiados en esta clase de trabajos.

Entre las características del delincuente, los antecedentes penales se han revelado como uno de los principales predictores de gravedad punitiva. La evaluación de las diferentes medidas relativas a condenas anteriores muestra ciertas dificultades, ya que algunas predicen mejor los resultados que otras (Welch et al., 1984). Los efectos de una detención o encarcelamiento previo pueden actuar de manera distinta en función del tipo de delito y también interactuar con el origen étnico, siendo considerada la conducta previa del delincuente más grave cuándo éste es hispano o negro en comparación con los delincuentes blancos (Vigorita, 2001; Zatz, 1984). Un estudio realizado por Crow (2008), basado en 567.061 casos representativos de la población condenada por delitos violentos, delitos relacionados con el tráfico de drogas y contra la propiedad entre los años 1994 y 2002 en Florida, reveló que la tasa de encarcelamiento se veía afectada de 
forma distinta en función de si existían o no registros anteriores, produciendo los antecedentes por delitos violentos mayor impacto en la probabilidad de encarcelamiento. Otros estudios han demostrado que la asunción de culpabilidad del acusado en la decisión judicial trae consigo un mayor riesgo de condena (Johnson 2003; Ulmer \& Bradley, 2006).

Coincidiendo con los anteriores estudios, una reciente investigación ha revelado que la existencia de un número mayor de condenas previas aumentó la probabilidad de una pena privativa de libertad y dio lugar a un período más largo de encarcelamiento (Sacks \& Ackerman, 2014). El estudio se basó en una muestra final de 634 casos de delitos graves de los diferentes condados de Nueva Jersey (EUA) con resoluciones que acordaban o no la libertad bajo fianza y que posteriormente fueron condenados. El dato más relevante de este estudio fue que los acusados en jurisdicciones no urbanas tenían mayor riesgo de ser condenados, confirmándose así la creencia de que los jueces de zonas no urbanas tienden a ser más punitivos que los jueces de áreas urbanas. Además, los hombres fueron condenados a penas más largas que las mujeres, siendo también más largas las penas que recibieron los acusados negros en comparación con los blancos.

Numerosos estudios han hallado diferencias en relación con el sexo del delincuente, llegando a la conclusión de que las mujeres tienen una probabilidad menor de ser encarceladas y reciben sentencias más leves que los hombres. La edad, en especial cuando interactúa con la etnia y el género, también es una variable relevante relacionada con la disparidad de las sentencias, por lo que algunos autores norteamericanos han señalado que ser joven, negro y de sexo masculino supone un alto coste en términos de riesgo de recibir un castigo más severo (Steffensmeier et al., 1998). La denominada "perspectiva de las preocupaciones centrales" ("focal concerns perspective") proporciona una base teórica para interpretar los estereotipos en las decisiones judiciales. De acuerdo con tal planteamiento, tres son las preocupaciones centrales que influyen en los jueces y en otros actores de la justicia penal a la hora de dictar sentencia: a) la culpabilidad del infractor y el grado de daño causado a la víctima; b) la protección de la comunidad y c) las implicaciones prácticas de la decisión, tanto organizacionales como individuales. No obstante, esta teorización tiene una deficiencia importante, ya que la opinión sobre la pena que merece el acusado aparece mezclada con la evaluación de los daños causados a la víctima, elementos que deberían ser 
claramente diferenciados. En lo que respecta a la culpabilidad del acusado, por lo general su análisis se centra en la biografía y en la peligrosidad percibida, mientras que las investigaciones sobre los delitos sexuales, como veremos a continuación, revelan que el impacto que recibe la víctima no es reconocido, por lo general, como un factor relevante en los análisis de sentencias. El citado estudio, con base en una amplia muestra de datos sobre sentencias dictadas en Pennsylvania entre 1989-1992 (n: 139.000), encontró que los efectos de género fueron los más significativos, seguidos de la edad y la etnia. La influencia de la edad depende del género, siendo mayor en los hombres que en las mujeres delincuentes. La relevancia de la etnia entre los hombres dependía de la edad: en los hombres más jóvenes tenía más influencia que en los de edad avanzada. (Steffensmeier et al., 1998).

La etnia ha sido uno de los temas más controvertidos. Numerosos estudios han confirmado que los miembros pertenecientes a minorías son condenados con más severidad que los delincuentes blancos. Según Demuth (2003), la disparidad puede explicarse como una consecuencia relativa a las creencias acerca de la peligrosidad del acusado sobre la base de su origen étnico. Las raíces del estereotipo no son fáciles de definir, ya que la etnia está relacionada con la pertenencia a una clase social baja y debería aclararse hasta qué punto se trata de una forma de discriminación racial o social.

Un lugar relevante en los análisis de sentencias ocupa la aportación de la psicología jurídica. Especialmente relevantes son en España los estudios de Garrido \& Herrero $(1995,1997)$ que revelaron la presencia del heurístico de anclaje en la actividad cognitiva de jueces y magistrados, hasta el punto de condicionar en un $81 \%$ de la decisión en delitos sexuales. Según un estudio de Arce, Fariña \& Novo (1996), el anclaje, analizado como la vinculación de la decisión judicial a la petición del Fiscal, afectaba a un $58 \%$ de las sentencias. Posteriormente Fariña, Arce \& Novo (2002) hallaron que un 63,6\% de las sentencias analizadas estaban guiadas por este efecto en la petición de la fiscalía o, en sentencias en segunda instancia, en la resolución judicial previa, con una profundidad inferior en la narración de los hechos, que afectaba a la motivación de las mismas. El efecto de anclaje aparece así como un sesgo contraprocesal que lleva aparejado un debilitamiento de la fundamentación jurídica y era más fuerte en los veredictos de culpabilidad que en los de inocencia. Sin embargo, según estos autores, las resoluciones en las que está ausente el heurístico de anclaje están 
guiadas por un proceso de integración de la información más completo y presentan una mayor orientación hacia los hechos, un mayor grado de motivación jurídica, una mayor actividad cognitiva y un procesamiento más profundo de la información.

\subsection{Delitos sexuales y abuso sexual infantil}

La investigación relativa a cómo el sistema penal responde a los delitos sexuales se ha centrado en diferentes aspectos, entre los examinados anteriormente. Uno de ellos ha sido la relación previa entre víctima y delincuente. Según diferentes estudios, los extraños están en mayor riesgo que los conocidos de llegar a juicio y, cuando son condenados, presentan mayor riesgo de recibir una pena de prisión. Este hallazgo se interpreta, sobre todo, como una confirmación de la renuencia de las instituciones, y en particular de los Tribunales penales, a tomar en serio los casos de abuso sexual cometidos en el grupo familiar o en instituciones como escuelas o el ejército, entre otros. Las diferencias se basan en la creencia de que un delito sexual cometido por un extraño es más grave, no porque los efectos sobre la víctima sean peores, sino porque el elemento aleatorio lo hace más temible para la comunidad.

Las características de la víctima han sido también analizadas, con el fín de comprobar si los casos en los que la víctima real está más cerca de la imagen preconcebida de "víctima ideal" son más seriamente tratados por los Tribunales que los de víctimas que tienen características que suelen asociarse con la presunción de que la víctima habría provocado o facilitado la comisión del delito por medio de una acción u omisión "culpable", tales como la participación en la prostitución, el consumo de drogas o alcohol o la aceptación de subir al coche del infractor.

También se han puesto de manifiesto diferencias respecto a la etnia cuando interviene como variable a analizar de forma conjunta con la relación entre víctima y delincuente. Se ha observado que el castigo es significativamente menor para delincuentes negros que agreden a conocidos también negros, en comparación con los acusados blancos y con los negros que agreden a víctimas blancas (Spohn \& Spears, 1996; Walsh, 1987).

Con respecto a los delitos sexuales, merecen ser destacados los estudios realizados por Kingsnorth. Los resultados de la investigación previa no han sido 
confirmados por un estudio basado en una muestra de 365 casos en el que no se encontró ninguna relación entre la díada etnia/relación víctima-ofensor y el sentido de la sentencia, ni en la decisión de encarcelar, ni en lo relativo a la determinación de la duración de la pena (Kingsnorth et al., 1998). Así, no se encontró apoyo a la tesis dominante que afirmaba la existencia de un efecto interactivo entre la variable étnica y la relación víctima-delincuente. Los autores sugieren una serie de hipótesis para explicar esta discrepancia en los resultados: una mayor sensibilidad en los últimos años, que habría mitigado anteriores concepciones racistas, el paso de penas indeterminadas a penas determinadas o diferencias en la composición de la muestra. Esta última cuestión metodológica debe ser destacada. Mientras que otros estudios incluyeron una serie de agresiones sexuales, estos autores limitaron los análisis a las formas más graves. Esto podría explicar las diferencias en los resultados, dado que la discrecionalidad suele considerarse asociada inversamente a la gravedad del delito y la discriminación está asociada a la discrecionalidad.

Otro estudio de Kingsnorth et al. (1999) debe ser destacado por su interés para los fines de nuestro trabajo. Tras analizar una muestra de 467 casos, se comprobó que ni la relación previa entre víctima y agresor ni las características de la víctima juegan un papel importante en la decisión de procesar o no al denunciado, llevar el caso a juicio, decidir sobre la culpabilidad del acusado o imponer una pena de prisión o una pena no privativa de libertad. Sin embargo, en los casos en que se condenaba a una pena de prisión ambas variables fueron predictoras de un castigo más severo, siendo su influencia significativa en cuanto a la duración de la pena. La muestra estaba compuesta por casos de agresión sexual enjuiciados por los Tribunales de Sacramento (EE.UU.), después de haber eliminado aquellos en los que estaban implicados autores menores de 18 años o víctimas menores de 14 años y algunos casos de delitos menos graves. Se consideró como características "negativas" de la víctima consumir alcohol y drogas, dedicarse a la prostitución, transitar sola por la vía pública de noche, hacer autostop, estar en un bar, ayudar al agresor quitándose su ropa y aceptar ser trasladada en el vehículo del agresor. La duración de la pena de prisión fue considerada como una variable continua y se halló que la existencia de relación previa entre víctima y acusado reducía la pena de prisión en 35 meses. Por otra parte, la presencia adicional de las 
mencionadas características "negativas" de la víctima redujo la pena de prisión en 17 meses por cada una de ellas.

En lo que atañe al abuso sexual infantil, la investigación sobre la respuesta del sistema penal se ha centrado principalmente en el análisis del flujo de casos, habiéndose revelado altas tasas de desestimación de casos. Estos estudios han mostrado que factores como la edad o el sexo de la víctima y la relación previa con el agresor desempeñan un papel relevante en las decisiones relativas a procesar o no al imputado o llevarlo o no a juicio (Bunting, 2008; Cross et al., 1994; Cross et al. 2003; Finkelhor et al., 2005; Martone et al,. 1996; Ménard \& Ruback, 2003; Sedlak et al., 2005; Stroud et al., 2000).

Un estudio de sentencias fue llevado a cabo por Levesque (2000), quien puso de manifiesto que las decisiones judiciales se fundamentan, básicamente, en el hecho de que el delincuente haya cometido delitos sexuales con anterioridad y en el número de víctimas que han sido abusadas. La muestra, compuesta por 387 víctimas, estaba formada por una serie de casos procesados entre 1987 y 1991 en una ciudad del este de los EUA. La duración de la pena de prisión fue de 3,5 años con una desviación estándar de 5,9 años. Los resultados reflejan una débil capacidad de predicción de las características de las víctimas, incluida la variable binaria que se refiere a la relación con el agresor (abuso intrafamiliar / extrafamiliar). El autor concluye que la respuesta que la justicia penal brinda a los delitos sexuales cometidos contra menores de edad presenta pocas diferencias con el tratamiento que reciben otros delitos graves.

De acuerdo con estos resultados, el sistema de justicia no se vería afectado por la oleada de leyes promulgadas contra los depredadores sexuales de niños. Las afirmaciones de que se está llevando a cabo una caza de brujas no obtendrían respaldo empírico, del mismo modo que tampoco resultan avaladas las voces que, por el contrario, critican que los delitos sexuales no son tomados en serio. Cabría así concluir que una vez el caso ha sido identificado por la oficina del Fiscal, estas preocupaciones carecen de fundamento. Levesque interpreta los resultados como una confirmación de que las víctimas no son justamente tratadas, ya que la duración de la pena de prisión depende de las características de los perpetradores y no del impacto del hecho en la víctima. No obstante, debe recordarse que este es un tema altamente controvertido y este hallazgo puede verse como algo intrínseco a la justicia penal, de modo que las 
necesidades de la víctima deberían satisfacerse por otros medios, más allá de la determinación de la respuesta punitiva frente al ofensor.

Por otra parte un estudio de Patrick \& Marsh (2011) estableció que las características del delito fueron mejores predictores en comparación con los rasgos de la víctima y con los del acusado. Los autores analizaron un total de 1.060 casos de abuso sexual infantil extraídos de las sentencias condenatorias dictadas en juicio o debido a una declaración de culpabilidad del acusado entre los años 2001 a 2007 en Idaho (EUA). Los resultados revelaron que la decisión de enviar a un condenado a prisión y la determinación de la duración de la pena de prisión forman parte de un proceso complejo en el que inciden una variedad de factores. Aunque las características de la víctima y el delincuente parecen afectar a la decisión del juez sentenciador, las circunstancias del delito lo hacen de forma mucho más determinante. Esta investigación es consistente con los resultados evidenciados en anteriores estudios, como el de McCormick et al. (1998), quienes afirmaron que los extraños y los conocidos tenían más probabilidad de ser condenados a penas más largas que quienes agredían a sus parejas o ex-parejas. El género de la víctima se mostró que tenía una influencia importante, pero no así su origen étnico. Los autores argumentan que este resultado no debe ser sobreestimado, al tratarse de un Estado poblado de forma homogénea por blancos.

Por su parte Holland \& Sheets (2009) examinaron si las características de los agresores y de las víctimas, tomadas en consideración de forma conjunta, influían en la pena impuesta. Utilizando los datos disponibles en un centro de asistencia a víctimas de agresión sexual (n:228) hallaron que a quienes habían agredido a víctimas vulnerables recibían, de promedio, penas un 43\% más largas en comparación con los agresores de víctimas no vulnerables. La construcción de la vulnerabilidad de la víctima estaba compuesta por tres variables: ser menor de 14 años, con problemas mentales y con un nivel inferior de inglés. Este hallazgo brinda apoyo a la perspectiva "caballerosa" o "paternalista". Sin embargo, el sexo y la etnia, tanto de la víctima como del agresor, no sirvieron para predecir el resultado de la sentencia. Los autores animan a los criminólogos a incorporar las características de la víctima a los modelos de predicción de los resultados de las sentencias.

Un reciente estudio comparó un grupo de delincuentes que sólo victimizaban a niños con un grupo de sujetos que agredía sólo a adultos, considerando incluidos en el 
segundo grupo a todas las víctimas mayores de 14 años (Amirault \& Beauregard, 2014). La muestra estaba compuesta por 519 delincuentes sexuales condenados en Quebec (Canadá). Las características del delito incrementaron la severidad de las sentencias dictadas contra quienes sólo victimizaban a adultos, mientras que los factores relativos al acusado influyeron en la gravedad de las condenas aplicadas a los acusados menores de edad. Al igual que en estudios anteriores, la gravedad de la pena disminuyó de forma significativa en ambos grupos de infractores en los casos de victimización intrafamiliar. El uso de armas en la comisión de los hechos también fue un predictor significativo de la duración de la pena. Entre las variables relativas a la víctima, dos fueron significativas: la edad y el daño físico. La duración de la condena se incrementó a mayor edad de la víctima y cuando había sufrido daños físicos. Sin embargo, atendiendo sólo a la muestra de agresores de menores de edad, ninguna de las características de la víctima pudo predecir una condena más severa.

Finalmente, algunos estudios han analizado la toma de decisiones de los procedimientos tramitados con Tribunal del jurado, ya sea simulado o real. Varios de ellos ratifican la observación de que, a la hora de enjuiciar delitos sexuales, los miembros del jurado se basan más en los factores extralegales en comparación con los Jueces de carrera (LaFree et al, 1985). Variables como el comportamiento de la víctima o la relación previa con su agresor influenciaron el juicio emitido por el jurado cuando la cuestión controvertida en el juicio se relacionaba con el consentimiento de la víctima. En España el estudio de Arce, Tortosa \& Alfaro (2003) también muestra una mayor propensión de los jurados hacia los factores extranormativos, además de una mayor inclinación hacia la posición de la defensa. Esta clase de conclusiones han sido refutadas por Kingsnorth et al. (1999), quienes sugieren que el movimiento de reforma de la legislación relativa a las agresiones sexuales habría logrado educar al público sobre la naturaleza y las dinámicas concurrentes en las agresiones sexuales.

En relación con el abuso sexual infantil, se han investigado los factores que pueden influir en las decisiones dictadas por los potenciales miembros de un jurado. Estos estudios han puesto de manifiesto que un incremento del número de veredictos de culpabilidad estaba relacionado con la denuncia inmediata de los hechos (Golding et al., 1999; Pozzulo et al., 2010). Sin embargo, existe poca investigación relativa al impacto que representa el sexo o la relación con la víctima (familiar frente a extraño). McCoy \& 
Gray (2007) encontraron un número más elevado de veredictos de culpabilidad respecto a hombres acusados que en mujeres. En cuanto a la relación entre víctima y delincuente, aparecieron más veredictos de culpabilidad en los casos de abuso intrafamiliar en comparación con la victimización extrafamiliar, pero la diferencia en la tasa de condena fue sólo significativa cuando el acusado era un hombre. Según los autores, tal diferencia se debió a la percepción potencial de los miembros del jurado, que consideraban que el incesto padre-hija era la mejor representación de un caso de abuso infantil "típico".

Uno de los factores analizados en la investigación de los miembros del jurado simulado ha sido la relevancia del género de los miembros del jurado. Según Pozzulo et al. (2010), el género fue el único factor predictor de la decisión del jurado, siendo las mujeres significativamente más propensas que los hombres a dictar un veredicto de culpabilidad. A la misma conclusión llegan Arce, Fariña \& Fraga (2000) al afirmar que las mujeres son más proclives a la culpabilidad que los hombres en los casos de violación, sin que ello signifique la existencia de sesgo hacia el acusado. Según este estudio las mujeres tienden a hacer un análisis más profundo de la información.

\section{Objetivos y metodología}

El estudio que se presenta tiene como finalidad conocer los factores que influyen en las decisiones judiciales relativas a la condena y la imposición de la pena de las personas acusadas por delitos sexuales contra menores de edad. Concretamente se examinará en qué modo estas decisiones están condicionadas por las características de la víctima, del acusado y del hecho enjuiciado. Asimismo se pretende conocer los efectos reales en la actividad sentenciadora de las peculiaridades de la legislación española, básicamente la mayor rigidez de su sistema de determinación de la pena, y en particular de la reforma de 2010 que ha endurecido el tratamiento punitivo de algunos delitos aquí tratados.

El conjunto de casos analizados está formado por todas las sentencias dictadas en primera instancia por diversas Audiencias Provinciales españolas sobre delitos sexuales en los que la víctima es menor de edad. Los datos se han extraído de la base de datos del CENDOJ (Centro de Documentación Judicial del Consejo General del Poder Judicial), de acceso público. Según la consulta realizada al Director del Centro, en ella se recogen todas las sentencias dictadas por órganos colegiados respecto a cualquier 
delito, incluidas las dictadas tras conformidad de las partes. Hemos descartado, por lo tanto, las sentencias de los Juzgados de lo Penal, pues al no estar recogidas en su totalidad en una base de datos única no ha sido posible acceder a ellas. Las sentencias analizadas contienen los pronunciamientos judiciales sobre los delitos de mayor gravedad, pues es competencia de las Audiencias Provinciales el conocimiento en primera instancia de los delitos con pena máxima de 5 o más años de prisión (art. 14 LECrim). Ello incluye gran parte de delitos sexuales contra menores de edad, especialmente aquellos que hacen referencia a una víctima menor de 13 años.

El análisis de las sentencias es poblacional, referido a Andalucía, Cataluña, Galicia y Madrid. La selección de estas comunidades autónomas obedece a un criterio de diversidad territorial y socio-cultural. El ámbito temporal comprende las sentencias dictadas entre 1 de enero de 2011 y 31 de diciembre de 2012. Con ello se pretende analizar el eventual impacto de la reforma penal de 22 de junio de 2010 (LO 5/2010), que modifica sustancialmente los delitos sexuales contra menores de edad.

Utilizando la base de datos indicada, se procedió a la búsqueda de sentencias a través de determinadas palabras clave, obteniéndose un resultado inicial de 2.421 sentencias $^{2}$. Una vez consultadas todas ellas, se descartaron las referidas a delitos sexuales con víctima mayor de edad, las dictadas en segunda instancia (recursos de apelación) y las sentencias repetidas o no relacionadas con los delitos aquí analizados, obteniéndose un total válido de 366 sentencias.

Aun siendo el objeto de análisis las sentencias, la unidad de medida adoptada ha sido la víctima del delito, de acuerdo con nuestros objetivos. El análisis empírico se ha focalizado en la víctima menor de edad, no en el acusado o en la decisión judicial, ya que en una misma sentencia puede haber diversas víctimas o diferentes pronunciamientos respecto a cada una de ellas. Esta decisión metodológica explica que los casos analizados sean superiores al número de sentencias (Tabla 1). El número total de víctimas es de 420 .

\footnotetext{
2 Las palabras clave utilizadas han sido: "abuso sexual", "pornografía", "corrupción Y menores", "corrupción de menores exhibicionismo y provocación sexual", "corrupción de menores", "agresión sexual”, "prostitución Y menores”, “prostitución Y menores Y matrimonio”, "prostitución E infantil”.
} 
Tabla 1. Sentencias analizadas y número de víctimas

\begin{tabular}{|l|c|c|c|}
\hline \multicolumn{1}{|c|}{ CC.AA. } & Sentencias consultadas & Sentencias válidas & Víctimas \\
\hline Andalucía & 668 & 125 & 127 \\
Cataluña & 649 & 119 & 150 \\
\hline Galicia & 200 & 32 & 35 \\
Madrid & 904 & 90 & 108 \\
\hline Total & 2421 & 366 & 420 \\
\hline
\end{tabular}

En este estudio se analiza qué variables influyen en la condena o absolución del acusado, en la duración de la pena de prisión, duración de la pena de multa y determinación de la cuantía de la responsabilidad civil. Para ello, se utilizan como variables independientes el tipo de delito $^{3}$, grado de ejecución, fecha de comisión ${ }^{4}$, datos sociodemográficos de los acusados y de las víctimas del delito (edad, género, nacionalidad), tipo de relación previa entre ellos ${ }^{5}$, quién ha dado la primera noticia al sistema de justicia penal ${ }^{6}$, circunstancias modificativas de la responsabilidad criminal $^{7}$, si la víctima ha sido testigo y, en su caso, si durante el proceso se adoptaron medidas de protección de la víctima-testigo ${ }^{8}$, presencia o ausencia de acusación particular en el proceso y género de los Magistrados que adoptaron la sentencia ${ }^{9}$.

Para el análisis de los datos obtenidos se utilizó el paquete estadístico STATA. Sobre las variables extraídas de las sentencias, complementamos el análisis bivariante

\footnotetext{
${ }^{3}$ Agrupadas en las siguientes categorías: agresión sexual, agresión sexual agravada, abuso sexual, abuso sexual agravado, abuso sexual con engaño, agresiones o abusos a menores de 13 años (art. 183 reforma 2010), prostitución de menores, exhibicionismo, pornografía de menores, corrupción de menores, otros.

${ }^{4}$ Hace referencia a si la fecha de comisión del hecho es anterior o no al 23-12-2010, la fecha de la entrada en vigor de la reforma penal de 22 de junio de 2010.

${ }^{5}$ Las categorías adoptadas son las siguientes: ascendiente, pareja de la madre o padre, otros familiares o convivientes, docente o análogo, conocido, desconocido, no consta.

${ }^{6}$ Las categorías son: víctima mayor de edad, padres, madre, padre, abuela, otros familiares, escuela, centro sanitario, otros, no consta.

7 Hace referencia a la existencia de circunstancias agravantes (reincidencia u otras) o atenuantes (cualificada, grave adicción a drogas, obcecación o estado pasional, confesión, reparación, dilaciones indebidas o analógica).

${ }^{8}$ Se categorizan como medidas de protección a la víctima-testigo: puerta cerrada, barrera física en juicio oral, videoconferencia, declaración anticipada o testigo protegido.

9 Respecto al género de los Magistrados, se analiza si la ponente es mujer, número de mujeres en el Tribunal (excluyendo al ponente) y el número total de mujeres (incluyendo al ponente).
} 
con uno multivariante, que proporciona una visión más ajustada a la realidad, al tener en cuenta todas las variables analizadas de forma conjunta. El análisis multivariante ha permitido establecer la asociación de las diversas variables explicativas, como las características de la víctima y del acusado o la composición del Tribunal, con las decisiones adoptadas; en particular, la condena o absolución del acusado y la severidad de la pena impuesta. En el caso de la condena, el modelo utilizado muestra que la capacidad predictiva es de un $44 \%$ de la variación en la variable dependiente. Algunas de las variables tienen relaciones estadísticamente significativas con la variable dependiente, aunque este dato tiene una relevancia secundaria al no tratarse de una muestra que trate de ser representativa o generalizable sino que es de tipo poblacional.

\section{Resultados}

\subsection{Casos analizados}

Como se puede observar en la Tabla 2, los delitos de abuso sexual, agresión sexual y agresiones y abusos a menores de 13 años representan un 77'6\% del total. El predominio de los delitos graves es consecuente con la exclusión de las sentencias de los Juzgados de lo Penal. Del total de casos, un $84 \%$ son delitos consumados y en un $17,9 \%$ se han apreciado circunstancias modificativas de la responsabilidad penal. 
Tabla 2. Tipo de delito

\begin{tabular}{|l|r|}
\hline \multicolumn{1}{|c|}{ Tipología delictiva } & Porcentaje \\
\hline Abuso sexual & 23,6 \\
Agresiones o abusos a menores de 13 años & 23,6 \\
\hline Agresión sexual & 15,2 \\
Pornografía de menores & 12,1 \\
\hline Abuso sexual agravado & 10,0 \\
Violación o agresión sexual agravada & 5,2 \\
\hline Corrupción de menores & 5,0 \\
Prostitución de menores & 2,1 \\
\hline Exhibicionismo & 2,1 \\
Otros & 1,0 \\
\hline N Total & 420 \\
\hline NB: el total de porcentajes puede no sumar 100 por los redondeos & \\
\hline
\end{tabular}

Respecto al género de las víctimas, un $69,8 \%$ son niñas y un $18,8 \%$ niños. En relación con la edad, la moda se sitúa en los 12-13 años y la mediana en los 12 años. Los acusados son en un $98,3 \%$ de género masculino y en un $66,9 \%$ son españoles. La mediana de edad en el momento del delito se sitúa alrededor de los 39 años, aunque existe una moda local en los 65 años. En cuanto a la relación previa con la víctima, el acusado era al menos un conocido en un $68 \%$ de casos. En más de un $38 \%$ la victimización es intrafamiliar. 
Tabla 3. Relación previa entre el acusado y la víctima

\begin{tabular}{|l|r|}
\hline & \multicolumn{2}{|c|}{ Porcentaje } \\
\hline Conocido & 26,4 \\
Desconocido & 23,3 \\
\hline Ascendiente & 15,0 \\
Otros familiares o convivientes & 13,1 \\
\hline Pareja de la madre o el padre & 10,5 \\
No consta & 8,6 \\
\hline Docente o análogo & 3,1 \\
Total & 420 \\
\hline
\end{tabular}

NB: el total de porcentajes puede no sumar 100 por los redondeos

Por otra parte, en un $47,6 \%$ de casos la víctima era parte en el proceso como acusación particular. La víctima ha sido testigo en un 68,4\% de ocasiones y se han adoptado medidas para su protección en un 16,4\%, aunque en la mayor parte de las sentencias no consta este dato (69,3\%). Respecto al género de los Magistrados, en el $82,9 \%$ de los casos alguno de los miembros es mujer, siendo ésta ponente en un 40,2\%.

\subsection{Variables que pueden influir en la condena o absolución}

El primer objetivo era el estudio de la decisión sobre la condena o absolución de la persona acusada. De los casos analizados en un $64,8 \%$ se ha dictado sentencia condenatoria después de celebrarse el juicio oral, un 12,1\% son condenas por sentencia de conformidad, en un $22,1 \%$ se trata de absoluciones después de juicio y un $1 \%$ son absoluciones por retirada de acusación. Para el análisis estadístico de los datos, se han descartado las sentencias por conformidad y las absoluciones por retirada de acusación pues en tales casos no hay una decisión por parte del Tribunal. Así pues, se parte de un porcentaje de condenas del 74,52\% y de absoluciones del $25,48 \%$, siendo el total de casos 365 . 
Según un análisis de regresión logístico de las variables que inciden en la probabilidad de condena, ésta no guarda relación con el tipo de delito enjuiciado ${ }^{10}$ (a pesar de que en el análisis bivariante sí que se observa esta relación). Tampoco se detecta mayor probabilidad de condena en función de la nacionalidad ( $\mathrm{OR}=0,733$; $\mathrm{p}=0,280$ si es extranjero) o la edad del acusado o de la edad de la víctima $(\mathrm{OR}=1,001$, $\mathrm{p}=0,408 ; \mathrm{OR}=0,977, \mathrm{p}=0,670)$.

Por otra parte, la probabilidad de condena aumenta cuando es más distante la previa relación de la víctima con el acusado. La probabilidad es mayor cuando se trata de un infractor desconocido $(\mathrm{OR}=11,899 ; \mathrm{p}=0,001)$ respecto a la categoría de referencia de ascendiente, seguido de los casos en que el acusado es docente o análogo $(\mathrm{OR}=7,529 ; \mathrm{p}=0,045)$ o un conocido $(\mathrm{OR}=4,827 ; \mathrm{p}=0,002)$. En cambio, la ratio de condena es menor en los casos de victimización intrafamiliar.

Respecto a las medidas de protección de la víctima, todas ellas tienen el efecto de incrementar la probabilidad de condena, excepto la celebración del juicio a puerta cerrada. La única medida en que la diferencia es significativa estadísticamente es la declaración anticipada $(\mathrm{OR}=3,950, \mathrm{p}=0,032)$. Sin embargo, la presencia de acusación particular en el proceso no aumenta significativamente la probabilidad de condena $(\mathrm{OR}=1,002 ; \mathrm{p}=0,828)$ y en cuanto al género de los miembros del Tribunal se observa que, a mayor presencia de mujeres, disminuye la probabilidad de condena en juicio, de modo estadísticamente significativo $(\mathrm{OR}=0,629 ; \mathrm{p}=0,029)$.

Finalmente, en relación con las comunidades autónomas donde se han dictado las sentencias, existen escasas diferencias, aunque, tomando como referencia Madrid, se ha hallado que la probabilidad de condena es inferior en Cataluña $(O R=0,263 ; p=0,026)$.

\subsection{Duración de la pena de prisión.}

En segundo lugar se han analizado las variables que pueden influir en la severidad de la pena impuesta. Respecto a la duración de la pena de prisión, y teniendo en cuenta que no todos los delitos presentan la misma frecuencia (ver Tabla 2), se observa una distribución muy asimétrica de los casos analizados (310), lo cual provoca que la media

10. El único delito con mayor probabilidad de condena es la corrupción de menores $(\mathrm{OR}=1,882)$ en relación con la categoría de referencia "delito de agresiones o abusos a menores de 13 años", pero no es un resultado estadísticamente significativo $(\mathrm{p}=0,609)$. 
(49,5 meses) se sitúe muy por encima de los 35 meses de mediana (Gráfico 1). El rango de variación oscila entre cero y 180 meses de prisión, encontrándose la mayor parte de casos, concretamente un $16 \%$, en los 24 meses. Con todo, existe alguna moda local, por ejemplo, la que se sitúa alrededor de los 100 meses.

\section{Gráfico 1. Duración de la pena de prisión}

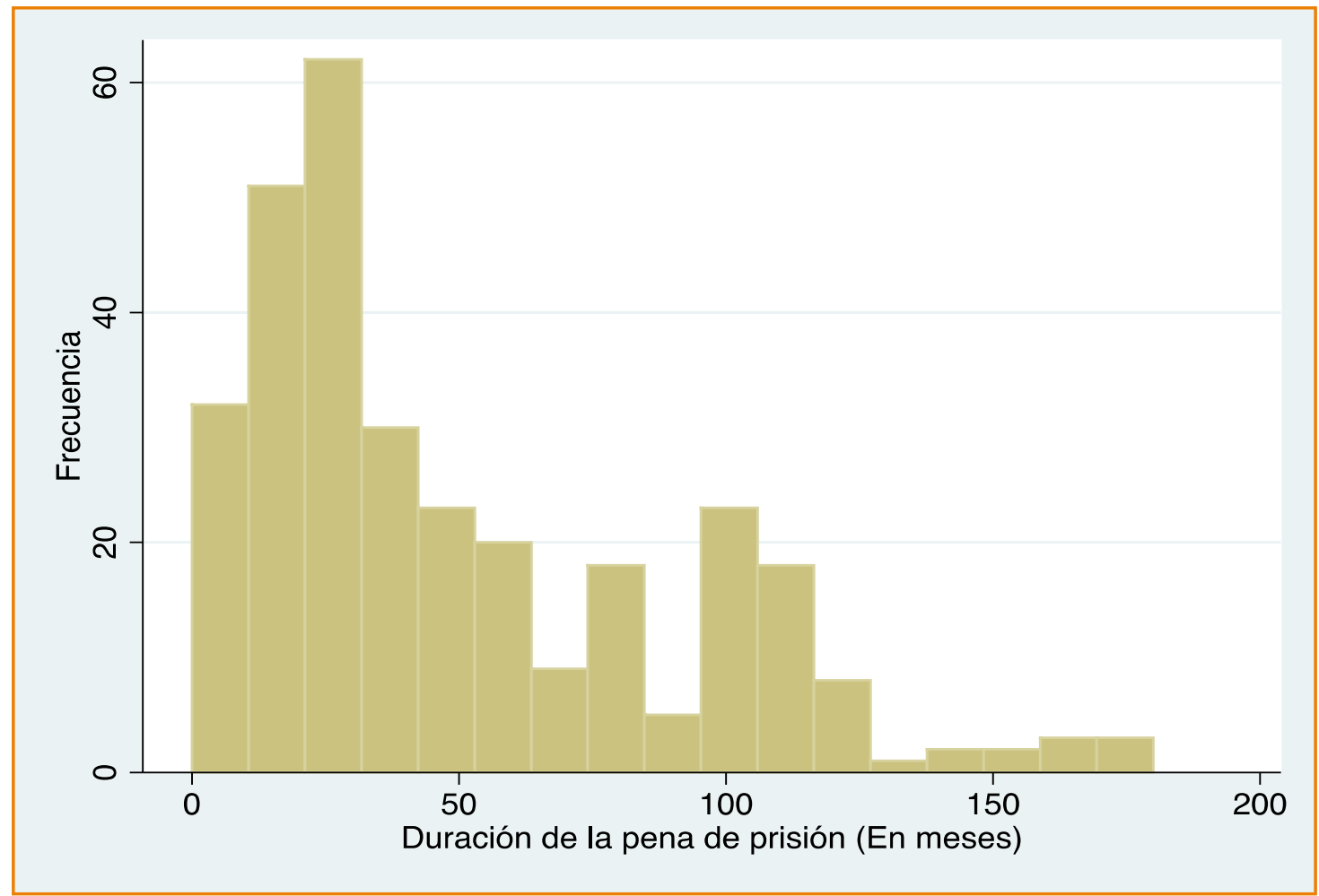

4.3.1 Tipo de delito, características del acusado y de la víctima y relación previa entre ambos.

El Gráfico 2 reproduce los resultados del análisis bivariante, referido a la distribución de la duración de la pena en relación con el tipo de delito. En el análisis multivariante se ha estimado un modelo de regresión lineal donde la variable dependiente es la duración de la pena. Las variables que identifican el tipo de delito se han combinado con las características de comisión del delito para crear unas nuevas variables interactivas. De este modo, el modelo estadístico ha encajado con el proceso decisorio del Tribunal. Los resultados ofrecen pocas sorpresas. La combinación de las variables referidas al tipo de 
delito y a las circunstancias modificativas de la responsabilidad penal es capaz de explicar en un 44\% la variación de la pena, porcentaje que alcanza el 45,44\% si se añade la variable referida al grado de ejecución del delito.

\section{Gráfico 2. Relación entre el delito y la pena de prisión}

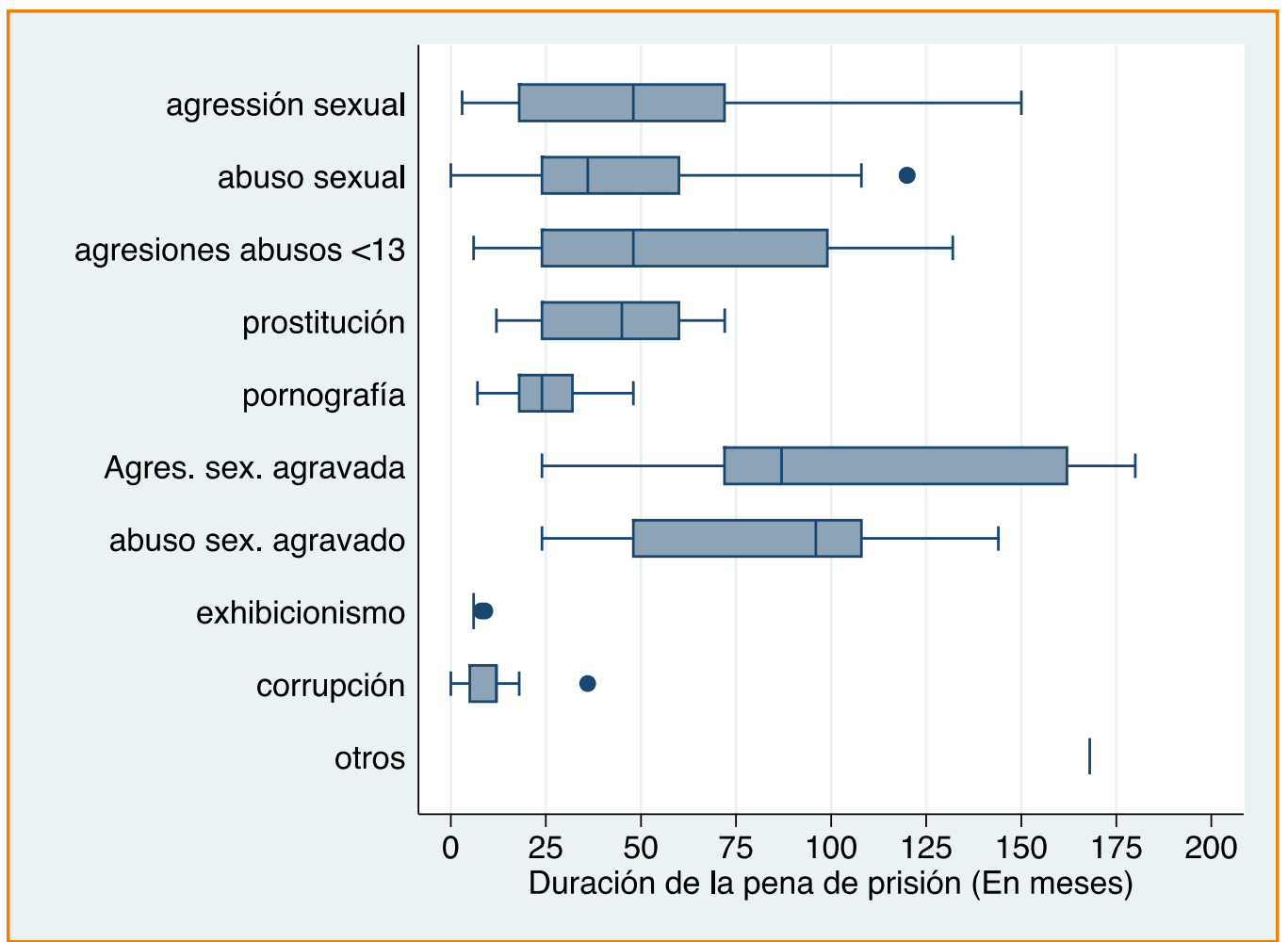

No se ha podido constatar que la entrada en vigor de la reforma del Código penal de 2010 haya tenido un efecto relevante en la duración de las penas impuestas, aun cuando las penas inferiores son más altas. En el análisis multivariante se confirma que las penas aumentan en casi cinco meses, aunque este coeficiente no es estadísticamente significativo. Ello debe ser atribuido en buena parte a la escasa cantidad de casos referidos a hechos posteriores a la reforma (tan sólo un $9 \%$ de la muestra).

En lo que atañe a las características sociodemográficas del condenado, no se observa una relación entre mayor severidad de la pena y que el condenado sea extranjero. El coeficiente estimado presenta un incremento de la pena en casi un mes y medio, lo cual no resulta significativo $(b=1,4 ; p=0,808)$. Respecto a la edad del condenado aparece un cierto efecto negativo sobre la pena $(b=-0,2)$ : por cada año de 
más que presenta el condenado, aumenta en casi seis días la pena de prisión, aun cuando este efecto no es significativo $(\mathrm{p}=0,369)$.

\section{Gráfico 3. Relación entre la edad de la víctima y la duración de la pena} impuesta

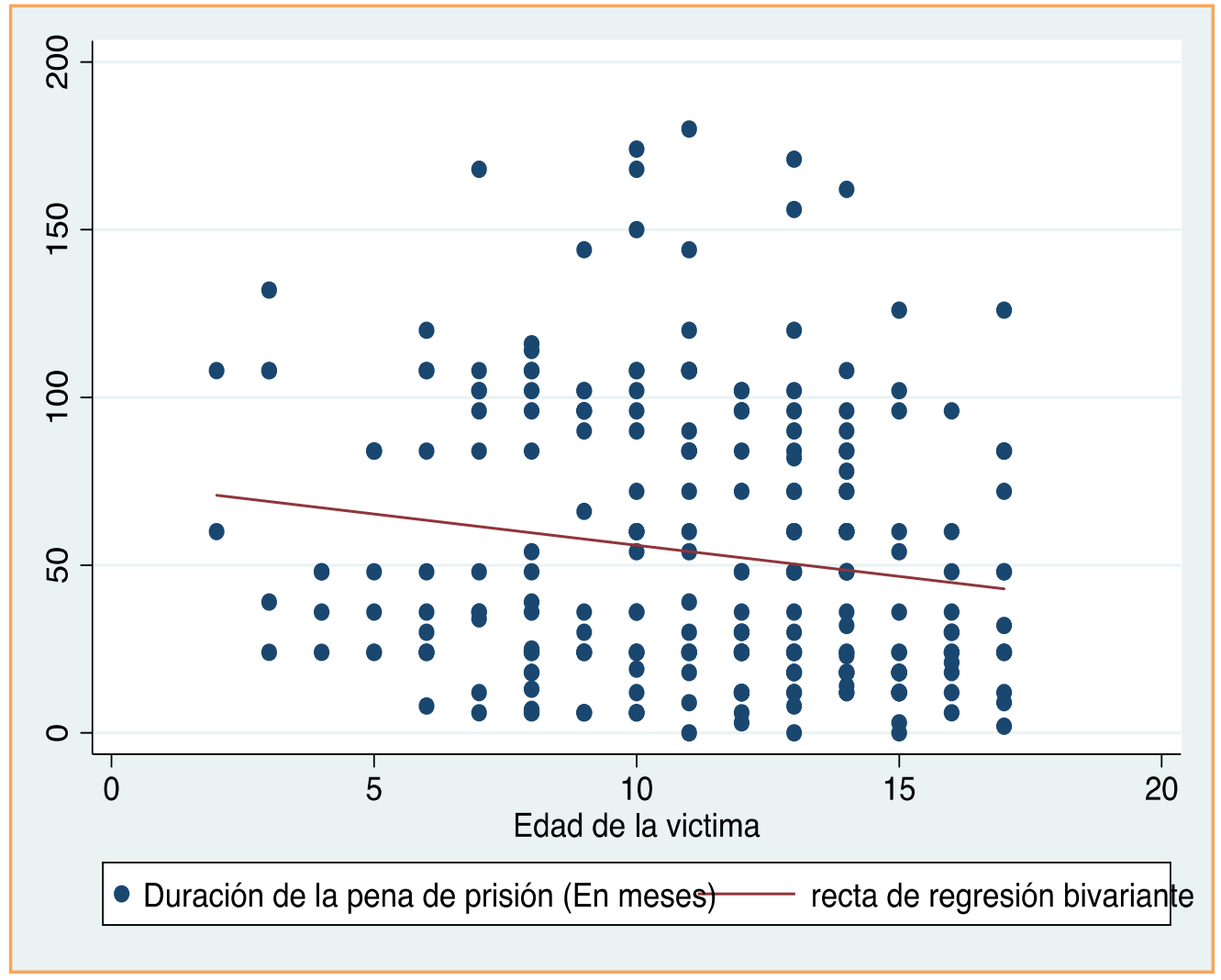

En cuanto a la edad de la víctima, el anterior gráfico de dispersión muestra una ligera relación negativa entre esta variable y la duración de la pena de prisión. Pese a ello, no se observa un salto cualitativo de pena en los casos en los que la víctima es menor de 13 años. El análisis multivariante confirma que la edad de la víctima posee un efecto negativo, estadísticamente significativo, sobre la pena impuesta al condenado $(b=-1,6)$. La pena de prisión se incrementa en algo más de un mes y medio por cada año que disminuye la edad de la víctima. Aparece ahí el mayor reproche jurídico de los casos en los que se percibe a la víctima como más inocente y vulnerable.

Respecto a la relación previa entre la víctima y el acusado, el análisis bivariante ofrece resultados diversos en función del tipo de relación (Gráfico 4). En los supuestos de victimización intrafamiliar - categoría que incluiría los ascendientes, pareja del padre 
o de la madre y otros familiares o convivientes- la media de pena impuesta es de veinte meses más de prisión respecto al restos de casos, diferencia que es significativa $(p=0,000)$. Parece que en estos casos, pese a disminuir la probabilidad de condena, cuando el pronunciamiento sea condenatorio la respuesta punitiva es más severa.

\section{Gráfico 4. Duración de la pena de prisión y relación previa entre víctima y condenado}

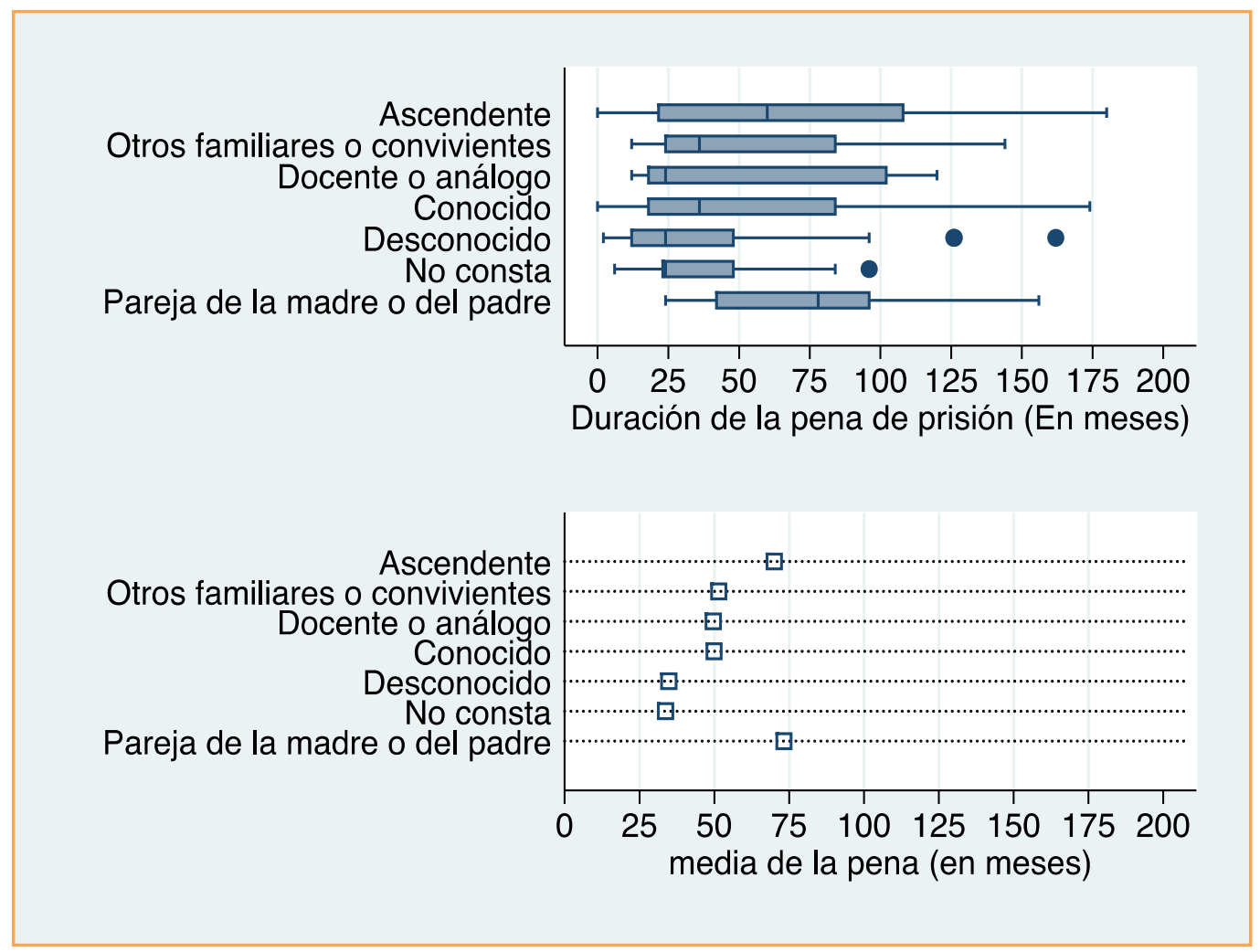

Sin embargo, en el análisis multivariante se matiza este resultado, al tener en cuenta la tipología delictiva. Todas las categorías analizadas presentan una duración de la pena de prisión menor que la de ascendiente, que se toma como referencia. La categoría en la que se impone menor pena de prisión es la de docente (33 meses menos), seguida de otros familiares o convivientes ( 23 meses menos), y ambas son significativas ( $p=0,019$ y $p=0,024$, respectivamente). Cuando el condenado es la pareja de la madre o del padre la pena se reduce en 10 meses respecto a la de los ascendientes, aunque la diferencia no es significativa $(p=0,320)$. 


\subsubsection{Características del proceso y de la sentencia}

En lo que concierne a la influencia que pueden tener las medidas de protección a la víctima en la duración de la pena de prisión se han hallado diferencias significativas en el análisis bivariante $(\mathrm{p}=0,0026)$. No obstante, las medidas de protección adoptadas pueden tener relación con la gravedad de los hechos enjuiciados, por lo que en el análisis multivariante la diferencia deja de ser significativa, con variaciones según los diferentes tipos de medidas. Así, la condición de testigo protegido, la declaración de la víctima en vídeo y la celebración del juicio oral a puerta cerrada producen aparecen asociadas a un incremento de la pena de prisión, mientras que la declaración anticipada de la víctima y la disposición de una barrera que evite la confrontación visual en el juicio se asocian a una disminución de la duración de la pena. El resultado no puede ser concluyente, pues los supuestos en los que se ha acordado alguna medida de protección representan tan sólo el 16,7\% del total de casos analizados.

Por otra parte, la participación de la víctima como acusación particular tendría un efecto débil, pero significativo $(\mathrm{p}=0,036)$, de incrementar la pena de prisión sobre el condenado, según un análisis bivariante. La diferencia es una media de 10 meses de prisión más para los acusados que se enfrentan a una acusación particular. Sin embargo, en un análisis multivariante, este resultado resulta contradicho. Así, el hecho de que la víctima o sus representantes legales contraten asistencia letrada apunta incluso a una disminución de la pena de prisión $(b=-0,5 ; \mathrm{p}=0,921)$. Pocas sorpresas ofrece, en cambio, la relación entre una conformidad entre la acusación y la defensa y una mayor benignidad de las sentencias condenatorias. En esta ocasión el análisis multivariante confirma los resultados del bivariante, mostrando una disminución de la pena impuesta en veinte meses $(b=-20,2 ; p=0,015)$.

En cuanto al género de los Magistrados, la presencia de mujeres en el Tribunal se ha analizado desde una triple perspectiva: se ha computado el número total de mujeres en el Tribunal, la presencia o ausencia de mujeres $\mathrm{y}$, finalmente, que el Tribunal sea presidido por una mujer. Según el análisis multivariante, ninguna de estas variables presenta un efecto sobre la duración de la pena acordada. Si se analiza el número total de mujeres, una Magistrada más produce el efecto de incrementar en más 
de dos meses la duración de la pena de prisión, aunque ello no es estadísticamente significativo.

Finalmente, la Comunidad Autónoma donde se ha cometido el delito tiene cierta relación con la severidad de la pena en un análisis multivariante, pues las penas acordadas en Andalucía, Cataluña y Galicia son menos duras que las de los Tribunales de Madrid, la cual se toma como categoría de referencia. La diferencia de Madrid respecto de Andalucía es significativa (al 10\% de nivel de significatividad, $\mathrm{p}=0,091$ ). Por otra parte, las penas acordadas por los Tribunales de las provincias más metropolitanas (Madrid y Barcelona) son de más larga duración que las del resto de provincias, resultado que es significativo estadísticamente en el análisis bivariante $(p=0,034)$ pero no lo es en el multivariante.

\subsection{Duración de la pena de días-multa y determinación de la responsabilidad civil}

La duración de la pena de multa presenta una distribución asimétrica. La mayor parte de casos se encuentran entre el cero y los 200 días-multa. Las variables independientes no son explicativas de la duración de la pena de días-multa.

En un $52,6 \%$ de los casos analizados la sentencia ha fijado responsabilidad civil directa derivada del delito. La cuantía de la misma presenta también una distribución muy asimétrica, con valores extraordinarios que se corresponden con casos de múltiples víctimas, que han sido eliminados para el análisis estadístico. Aun así, la distribución continua siendo asimétrica, pero es más adecuada para identificar tendencias generales.

Las capacidad predictiva de las variables independientes respecto a la cuantía de la responsabilidad civil es menor que la mostrada en la determinación de la pena de prisión. Una explicación estaría en que la cuantía de la responsabilidad civil no se encuentra prevista legalmente, a diferencia de la sanción penal. Con todo, se observan algunas tendencias generales. La primera de ellas es que los delitos relativos a la pornografía infantil dan lugar a cantidades más elevadas. En segundo lugar, la cuantía es mayor en los casos de victimización intrafamiliar, aunque esta relación no es estadísticamente significativa. En las categorías de docente, conocido, desconocido la cuantía de la indemnización es menor, tomando como categoría de referencia la de 
ascendiente. Finalmente, otras variables que se acercan o superan la significatividad estadística son las sentencias dictadas por conformidad y la medida de testimonio protegido. En ambos casos, los Tribunales tienden a fijar indemnizaciones más bajas.

\section{Discusión}

La interpretación de los hallazgos expuestos debe efectuarse con cautela, dada la inexistencia de previos estudios en España y en sistemas jurídicos próximos. La comparación con los resultados de la investigación desarrollada en países anglosajones debe partir de la diferencia sustancial que supone su mayor margen de discrecionalidad judicial a la hora de determinar la pena a imponer, además de otras diferencias menos evidentes relativas al contexto sociopolítico o a la cultura judicial.

Un aspecto a examinar es el modo en que el sistema de justicia penal selecciona los casos. Dada la elevadísima cifra negra existente, las posibilidades de una desviación respecto de la realidad de la delincuencia son muy elevadas. Sin embargo, ha podido comprobarse que los casos enjuiciados se corresponden en diversos aspectos con la fenomenología del abuso sexual infantil, como el hecho de que el perpetrador sea en una mayoría de casos una persona conocida o la elevada presencia de victimización intrafamiliar (un 38\%). Los resultados son también consecuentes con lo que muestran los estudios empíricos en cuanto a la distribución por sexo de las víctimas, aunque algo menos respecto a la edad. En las sentencias analizadas la edad de las víctimas se encuentra en un rango entre 2 y 17 años, con una media de 11 años. Se confirma así la intuición de que llegan menos a juicio los casos con víctimas de edad más reducida.

Si nos adentramos en el análisis de las variables, se observa que las características de la víctima y del acusado son, en general, poco relevantes como predictores de la decisión de condenar y de la extensión de la pena de prisión. Se confirmaría así este rasgo diferencial de los delitos sexuales, en los que tienen más preponderancia las características del hecho delictivo. Este rasgo aparece más acusado aquí que en los estudios realizados en los EUA, algunos de los cuales reflejan cómo los Tribunales tienen en cuenta, en mayor medida, las características del infractor. Una explicación de esta peculiaridad de la justicia española puede estar, en cuanto a la determinación de la pena, en el sistema legal, que obliga a valorar más las 
características objetivas del hecho mediante la definición legal de los elementos de las diversas tipologías delictivas, que las del perpetrador. En todo caso, tanto si atendemos a este resultado como a la extensión de las penas impuestas, valoradas en comparación con los máximos de pena legalmente imponibles para los delitos de esta clase que enjuician las Audiencias Provinciales, puede concluirse que los Tribunales no participan en la supuesta caza de brujas contra quienes cometen delitos sexuales contra menores de edad, denunciada desde algunos sectores. Es destacable, en este sentido, que la mediana de penas impuestas es de menos de tres años de prisión, siendo casi la mitad de los delitos enjuiciados agresiones sexuales, abusos sexuales y abusos sexuales a menores de trece años, para los que la ley prevé penas que pueden llegar hasta los ocho, doce o quince años de prisión según los casos. Las penas más graves se concentran en un número reducido de casos, prevaleciendo en general la moderación punitiva dentro del marco legal disponible. Por otra parte, el efecto real de la entrada en vigor de la reforma de 2010, que introduce un importante incremento punitivo en los delitos examinados, no ha podido comprobarse de un modo concluyente, lo cual haría necesario un posterior análisis una vez transcurrido más tiempo desde la referida reforma.

En relación con la tasa de condena no se han hallado diferencias significativas entre la mayor parte de variables independientes. Ello vendría a confirmar la hipótesis de la irrelevancia del tipo de delito (pese a ser la pornografía infantil el único en que la tasa de condena es más elevada) y la presunción según la cual la decisión de condenar o absolver no estaría condicionada por factores extrínsecos a la valoración de la prueba practicada en el juicio. La excepción es la relevancia de la relación previa entre acusado y víctima, siendo la tasa de condena significativamente más alta en caso de victimización por parte de personas desconocidas. El hallazgo es de gran transcendencia, pues ratifica lo establecido en la mayor parte de estudios y muestra la mayor dificultad de que recaiga condena en los casos de victimización intrafamiliar. Ello puede ser explicado en parte por los problemas probatorios existentes cuando el victimario es conocido, más aún si es alguien del entorno familiar, dado que la víctima testigo se encuentra sujeta a una mayor presión, aunque no cabe descartar la presencia de otros motivos relacionados con una mayor reticencia de los Jueces a tomar seriamente la victimización intrafamiliar, con creencias relativas a los efectos nocivos que una condena puede representar para la convivencia y armonía del grupo familiar o 
con el miedo al agresor desconocido. Por ello éste es un aspecto en el que una mayor investigación puede resultar de gran utilidad.

Este último hallazgo supone una aparente paradoja con la tendencia de los Tribunales a imponer penas más gravosas según aumenta la proximidad entre autor y víctima. Sin embargo, este resultado, ya de por sí poco concluyente en virtud del análisis multivariante, no debería sorprender si se tiene en cuenta que los Jueces están legalmente obligados a imponer la pena en su mitad superior en los delitos de agresión y abuso sexual cometidos por ascendientes o tutores y otras personas en virtud del art. 192-2 CPE. Tampoco debería causar extrañeza que las reticencias de los Jueces a condenar se mostraran en mayor medida en los casos de menor gravedad.

La mayor parte de sentencias no dejan constancia de si se han adoptado en el proceso medidas de protección para prevenir la victimización secundaria y cuando éstas han existido han mostrado una escasa influencia sobre la decisión de condenar. Una importante excepción es la declaración anticipada de la víctima, que determina una mayor probabilidad de condena. El hecho de que los casos de declaración anticipada aparezcan asociados a penas de prisión de menor duración nos está revelando que los Jueces tienden a acordar con mayor frecuencia la declaración anticipada de la víctima en casos de menor gravedad. Con todo, el hallazgo brinda un relevante apoyo a la validez de esta medida de protección, al refutar la creencia según la cual la declaración anticipada supone un riesgo para la prueba y para la condena del caso.

Por otra parte, dada la singularidad que supone el amplio poder que la ley procesal española otorga a la acusación particular, era de gran importancia evaluar su impacto en esta clase de delitos, en los que la acusación frecuentemente tiene que enfrentarse a dificultades probatorias y de toda índole. Nuestro estudio, al poner de manifiesto que la existencia de acusación particular no influye sobre la probabilidad de condena ni, según revela el análisis multivariante, sobre la gravedad de la pena impuesta, no permite validar la acusación particular como un instrumento eficaz desde la perspectiva de quien vincule la defensa de los intereses de las víctimas con el castigo del agresor. Por otra parte, el resultado no debería sorprender si se tienen en cuenta los estudios de psicología jurídica que han probado el efecto de anclaje que la posición del Fiscal ejerce sobre la actividad decisora de los jueces. 
Otro aspecto en el que nuestro estudio podía aportar mayor conocimiento, el relativo al sexo de los Magistrados, no confirma la presunción según la cual las mujeres tendrían una tendencia más punitiva en este tipo de delitos, hasta el punto de que el resultado obtenido sería incluso contrario al esperado, pues al aumentar la presencia de mujeres en el Tribunal disminuye la probabilidad de condena.

La comparación de los resultados por territorios aporta escasas diferencias significativas. Las únicas de ellas son la menor tasa de condena en Cataluña y penas más suaves en Andalucía, que tan sólo como hipótesis cabría explicar como reflejo del predominio de una ideología progresista frente a una cosmovisión conservadora predominante en Madrid y Galicia. La imposición de penas más graves en Madrid y Barcelona frente a Andalucía y Galicia podría apuntar una evolución hacia una mayor sensibilidad ante estos delitos en las comunidades más urbanizadas frente a las más rurales, pero las diferencias no resultan significativas y contradicen los resultados de los estudios efectuados en los EUA, que señalan un mayor reproche ante los delitos sexuales en el entorno rural que en el urbano. La evolución de la sensibilidad social ante el fenómeno aquí tratado es una cuestión compleja que no cabe analizar mediante categorías generales como las indicadas y para conocer en que modo los Jueces son permeables a esa evolución son necesarias otras técnicas de estudio, que complementen los análisis cuantitativos con una investigación de carácter cualitativo.

En relación con la duración de la pena de prisión impuesta, además de las cuestiones ya comentadas, el análisis de regresión múltiple ha permitido establecer que la combinación de las variables tipo de delito, circunstancia modificativa y grado de ejecución es capaz de explicar una buena parte de la variación de la variable dependiente. Se confirma así que el rígido sistema penológico del código penal español determina en una medida considerable la valoración judicial respecto a la pena impuesta en la sentencia. Más allá de los defectos propios de este sistema, la comparación con los resultados de la investigación realizada en países anglosajones permite plantear la hipótesis de si un sistema como el español, al limitar más la discrecionalidad judicial, reduce el riesgo de discriminación, hipótesis cuya verificación requeriría una investigación internacional de carácter comparado. No puede olvidarse, en todo caso, que este estudio se ha centrado en casos graves, en los que la discrecionalidad y, por consiguiente, el riesgo de discriminación, suele considerarse menor. 
En cuanto a las características de la víctima y del acusado la única variable que condiciona la severidad punitiva es la edad de la víctima. Este hallazgo tiene gran relevancia, dado que hasta la reforma de 2010 los Jueces no estaban obligados a tener en cuenta este hecho a la hora de individualizar la respuesta punitiva, siendo, como se ha señalado, el número de casos juzgados de acuerdo con la nueva norma, muy reducido. Se confirman así las conclusiones de otros estudios que indican que los jueces deciden incrementar la pena a medida que disminuye la edad de la víctima, reflejando así el mayor reproche social que reciben los abusos sexuales a niños de corta edad.

Otros resultados, como la mayor benignidad de la pena impuesta en los casos de conformidad previa al juicio entre la acusación y la defensa del acusado, no hacen sino ratificar la percepción habitual de que la disminución de la pena solicitada por parte de la acusación desempeña un papel esencial en la negociación que da lugar al acuerdo entre las partes, no siendo los delitos aquí examinados una excepción a esta regla.

Finalmente, el estudio aporta pocos datos relevantes respecto a la responsabilidad civil, que tiene una importancia destacable en estos delitos, en los que en una mayoría de casos se acuerdan indemnizaciones a favor de las víctimas, en general por concepto de daños morales, por lo que la discrecionalidad de los Tribunales a la hora de fijar el quantum es casi absoluta. Las variables aquí examinadas no tienen una influencia clara en la decisión judicial, lo cual sugiere que los Jueces tienen en cuenta esencialmente aspectos del caso concreto que les permiten valorar el impacto del delito en la víctima.

\section{Conclusiones}

El estudio ha permitido unos primeros avances en el conocimiento del modo en el que el sistema de justicia penal responde a los casos denunciados de victimización sexual contra menores de edad. La escasez de estudios previos y las limitaciones de este trabajo demandan ulteriores esfuerzos en esta línea de investigación, de crucial importancia victimológica. Asimismo se ha puesto de manifiesto la utilidad del análisis multivariante, que en diversos aspectos ha corregido los resultados del bivariante.

Los resultados confirman la importancia del fenómeno de la victimización intrafamiliar y apuntan a la existencia de dificultades para que el sistema de justicia 
penal procese hasta sus últimas consecuencias las denuncias de abusos menos graves cometidos en el entorno del menor. Ello tiene implicaciones en el sentido de explorar la viabilidad de mecanismos no punitivos para dar respuesta a estas situaciones, amén de mejorar el funcionamiento de los medios de prueba y hacer esfuerzos en la formación de jueces y fiscales en relación con estos casos. La necesidad de reforzar los medios de prueba debe tener en cuenta especialmente la protección de los menores que deben declarar como testigos, dado que el estudio respalda la declaración anticipada del menor como medio de prueba válido y eficaz.

Por otra parte, los resultados no avalan el recurso a la acusación particular como forma eficaz de protección de los intereses de la víctima. En el momento en que España debe cumplir con la Directiva europea de 25 de octubre de 2012 mediante la elaboración de un estatuto jurídico de la víctima, esta conclusión brinda argumentos a la posición que reclama una revisión profunda de esta excepcionalidad procesal y sostiene que el apoyo a las víctimas de estos delitos debe efectuarse por otros medios, básicamente mediante el refuerzo de un sistema de asistencia jurídica y psicológica gratuita y accesible.

\section{Agradecimientos}

Agradecemos a Aina Grueso su colaboración en la obtención y tratamiento de los datos extraídos de las sentencias judiciales.

\section{Financiación}

Este trabajo se ha realizado en el seno del Grupo de investigación sobre el Sistema de Justicia penal, con el apoyo del proyecto de investigación "La victimización sexual de menores y su protección penal" del Ministerio de Ciencia y Competitividad (2013-2015, Universitat Oberta de Catalunya, IP Josep M. Tamarit).

\section{Referencias}

Arce, R., Fariña, F., \& Novo, M. (1996). Cognitive activity in sentencing. VI European Conference on Psychology and Law. Siena.

Arce, R., Fariña, F., \& Fraga, A.I. (2000). Género y formación de juicios en caso de violación. Psicothema. 12, 623-628. 
Arce. R., Tortosa, F., \& Alfaro, E. (2003). Veredictos y análisis del contenido de las deliberaciones de los Tribunales de Jueces y Jurados en el contexto jurídico español. Psicothema, 15 (1), 127-135.

Amirault, J., \& Beauregard, E. (2014). The Impact of Aggravating and Mitigating Factors on the Sentence Severity of Sex Offenders: An Exploration and Comparison of Differences Between Offending Groups. Criminal Justice Policy Review, 25(1), 78-104.

Black, D (1976). The Behaviour of Law. New York: Academic Press.

Bunting, L. (2008). Sexual offences against children: An exploration of attrition in the Northern Ireland criminal justice system. Child Abuse \& Neglect, 32, 11091118.

Cross, T. P., DeVos, E., \& Whitcomb, D. (1994). Prosecution of child sexual abuse: Which cases are accepted? Child Abuse \& Neglect,18, 663-677.

Cross, T.P., Walsh, W., Simone, M., \& Jones, L.M. (2003). Prosecution of child abuse: A meta-analysis of rates of criminal justice decisions. Trauma,Violence and Abuse, 4, 323-340

Crow, M. S. (2008). The complexities of prior record, race, ethnicity, and policy. Criminal Justice Review, 33(4), 502-523.

Demuth, S. (2003). Racial and ethnic differences in pretrial release decisions and outcomes: A

comparison of Hispanic, black and white felony arrestees. Criminology,41, 873907

Fariña, F., Arce, R. \& Novo, M. (2002). Heurístico de anclaje en las decisiones judiciales. Psicothema, 14 (1), 39-46.

Finkelhor, D., Ormrod, R.K., Turner, H.A., \& Hamby, S.L. (2005). The victimization of children and youth: A comprehensive, national survey. Child Maltreatment $10(1), 5-25$.

Garrido, E., \& Herrero, C. (1995). Fiscales y jueces: concordancia entre percepción y realidad. En E. Garrido \& C. Herrero (Eds.), Psicología política, jurídica y ambiental, 269-281. Salamanca: Eudema.

Garrido, E. \& Herrero, C. (1997). Influence of the prosecutor's plea on the judge's sentencing in sexual crimes: hypothesis of the theory of anchoring by Tversky y Kahneman. En S. Redondo, V. Garrido, J. Pérez, \& Barberet, R. (Eds.), Advances in psychology and law. International contributions. Berlín: Walter de Gruyter. 
Golding, J.M., Sego, S.A. \& Sánchez, R.P., (1999). The effect of multiple childhood sexual assaults on mock jurors' perceptions of repressed memories, Behavioural Sciences and the Law, 17, 483-493.

Holland, D., \& Sheets, A. (2009).Sexual Assault and Sentencing: An Examination of Victim and Perpetrator Characteristics.Journal of Criminology and Criminal Justice Research \& Education, 3 (1), 1-10.

Johnson, B (2003). Racial and ethnic disparities in sentencing departures across models of conviction. Criminology, 41, 449-488.

Kingsnorth, R., López, J., Wentworth, J., \& Cummings, D. (1998). Adult Sexual Assault: the role of racial/ethnic composition in prosecution and sentencing. Journal of Criminal Justice, 26 (5), 359-371.

Kingsnorth, R., MacIntosh, R.C., \& Wentworth, J. (1999). Sexual Assault: the role of prior relationship and victim characteristics in case processing. Justice Quarterly, 16(2), 275- 297.

LaFree,G., Reskin, B.F. \& Visher, C.A. (1985). Jurors' responses to victims behavior and legal issues in sexual assault trials. Social Problems 32 (4), 389-407.

Levevesque, R.J.R. (2000). Sentencing Sex Crimes against children: an empirical and policy analysis. Behavioral Sciences and the Law, 18, 331-341.

Martone, M., Jaudes, P. K. \& Cavins, M. K. (1996). Criminal prosecution of child sexual abuse cases. Child Abuse \& Neglect, 20 (5), 457-464.

McCormick, J.S., Maric, A., Seto, M.C., \& Barbaree, H.E. (1998). Relationship to victim predicts sentence length in sexual assault cases. Journal of Interpersonal Violence, 13(3), 413-420.

McCoy, M.L.\& Gray, J.M. (2007). The impact of defendant gender and relationship to victim on juror decisions in a child sexual abuse case. Journal of Applied Social Psychology, 37, 1578-1593.

Ménard, K.S. \& Ruback, R.B (2003). Prevalence and processing of child sexual abuse: A multi-data-set analysis of urban and rural counties. Law and Human Behavior, 27(4), 385-402.

Myers, M. A. \& Talarico, S. M. (1986). Urban justice, rural injustice? Urbanization and its effect on sentencing. Criminology, 24(2), 367-392.

Patrick, S. \& Marsh, R. (2011). Sentencing Outcomes of Convicted Child Sex Offences. Journal of Child Sexual Abuse, 20, 94-108. 
Pozzulo, J.D., Dempsey, J.L. \& Crescini, H. (2010). Factors Affecting Decisions in Historic Child Sexual Abuse Cases Involving Continuous Memories. Criminal Justice and Behavior, 37, 951-964.

Sacks, M., \& Ackerman A.R. (2014). Bail and Sentencing: Does Pretrial Detention Lead to Harsher Punishment?. Criminal Justice Policy Review, 25(1), 59-77.

Spohn, C. \& Spears, J. (1996). The effect of offender and victim characteristics on sexual assault case processing decisions. Justice Quarterly, 13, 649-679.

Steffensmeier, D., Ulmer, J. \& Kramer, J. (1998). The interaction of race, gender and age in criminal sentencing: the punishment cost of being young, black and male. Criminology, 34 (4), $763-798$.

Sternberg, K.J., Lamb, M.E.\& Hershkowitz, I. (1996). Child Sexual Abuse Investigations in Israel. En Criminal Justice and Behavior, 23 (2), 322-337.

Stroud, D. D., Martens, S. L. \& Barker, J. (2000). Criminal investigation of child sexual abuse: A comparison of cases referred to the prosecutor to those not referred. Child Abuse \& Neglect, 24(5), 689-700.

Tamarit,J.M. (2013), La respuesta jurídica ante la victimización de menores. En N. Pereda \& J. M. Tamarit. Victimología teórica y aplicada. Barcelona: Huygens, 137-158.

Ulmer, J.T., \& Bradley, M. (2006). Variation in trial penalties among serious violent offenses. Criminology, 44, 631-670.

Vigorita, M. S. (2001). Prior offense type and the probability of incarceration: The importance of current offense type and sentencing jurisdiction. Journal of Contemporary Criminal Justice, 17(2), 167-193.

Walsh, A. (1987). The sexual stratification hypothesis and sexual assault in light of changing conceptions of race. Criminology, 25, 153-173.

Welch, S., Gruhl, J. \& Spohn, C. (1984). Sentencing: The influence of alternative measures of prior record. Criminology, 22 (2), 215-227

Zatz, M. (1984). Race, ethnicity, and determinate sentencing: A new dimension to an old controversy. Criminology,22, 147-71.

Josep M. Tamarit Sumalla es catedrático de Derecho penal en la Universidad de Lleida y en la Universidad Oberta de Cataluña. Es coordinador del Grupo consolidado de investigación sobre el sistema de justicia penal y su actividad investigadora está centrada en la victimología, la justicia restaurativa y el sistema de sanciones penales. 
Maria Jesús Guardiola Lago es profesora asociada de Derecho penal en la Universidad Autónoma de Barcelona, acreditada como profesora agregada por la AQU desde 2012. Doctora por la Universidad de Lleida (2005), realizó una estancia de investigación post-doctoral de dos años de duración en la Universidad de Lieja (Bélgica), siendo posteriormente becaria Juan de la Cierva en la UAB. Ha sido Magistrada suplente en la Audiencia Provincial de Tarragona y de Lleida. Sus principales líneas de investigación son: trata de seres humanos, inmigración irregular, sanciones penales, justicia restaurativa y mediación penal.

Patricia Hernández Hidalgo es Licenciada en Derecho y Criminología por la Universidad de Barcelona y Máster en Derecho y Penal y en Criminología, Política Criminal y Seguridad por la misma universidad. En la actualidad es Profesora de Criminología en la Universidad Oberta de Cataluña y está realizando su tesis doctoral sobre la violencia de pareja y la respuesta del sistema de justicia penal. Sus principales áreas de investigación son la victimización en las relaciones familiares y entre próximos, la respuesta del sistema de justicia penal y la justicia restaurativa, entre otras. Con anterioridad, ejerció varios años como abogada penalista.

Albert Padró-Solanet es licenciado en Filosofía y Máster en Ciencia Política y Máster en Administración Pública (Universidad Autónoma de Barcelona). Ha trabajado como investigador del comportamiento electoral y como analista del comportamiento de los consumidores en el ámbito privado. Actualmente es profesor de los Estudios de Derecho y Ciencia Política de la Universidad Oberta de Cataluña. Es profesor responsable de asignaturas metodológicas en el Grado de Criminología y en los Másteres de Análisis Político y de Administración Electrónica. Su principal área de interés son los modelos racionales de elección y el efecto de la las instituciones y la comunicación en el comportamiento político y social. 


\section{Anexos}

Tabla A1. Regresión logística binomial

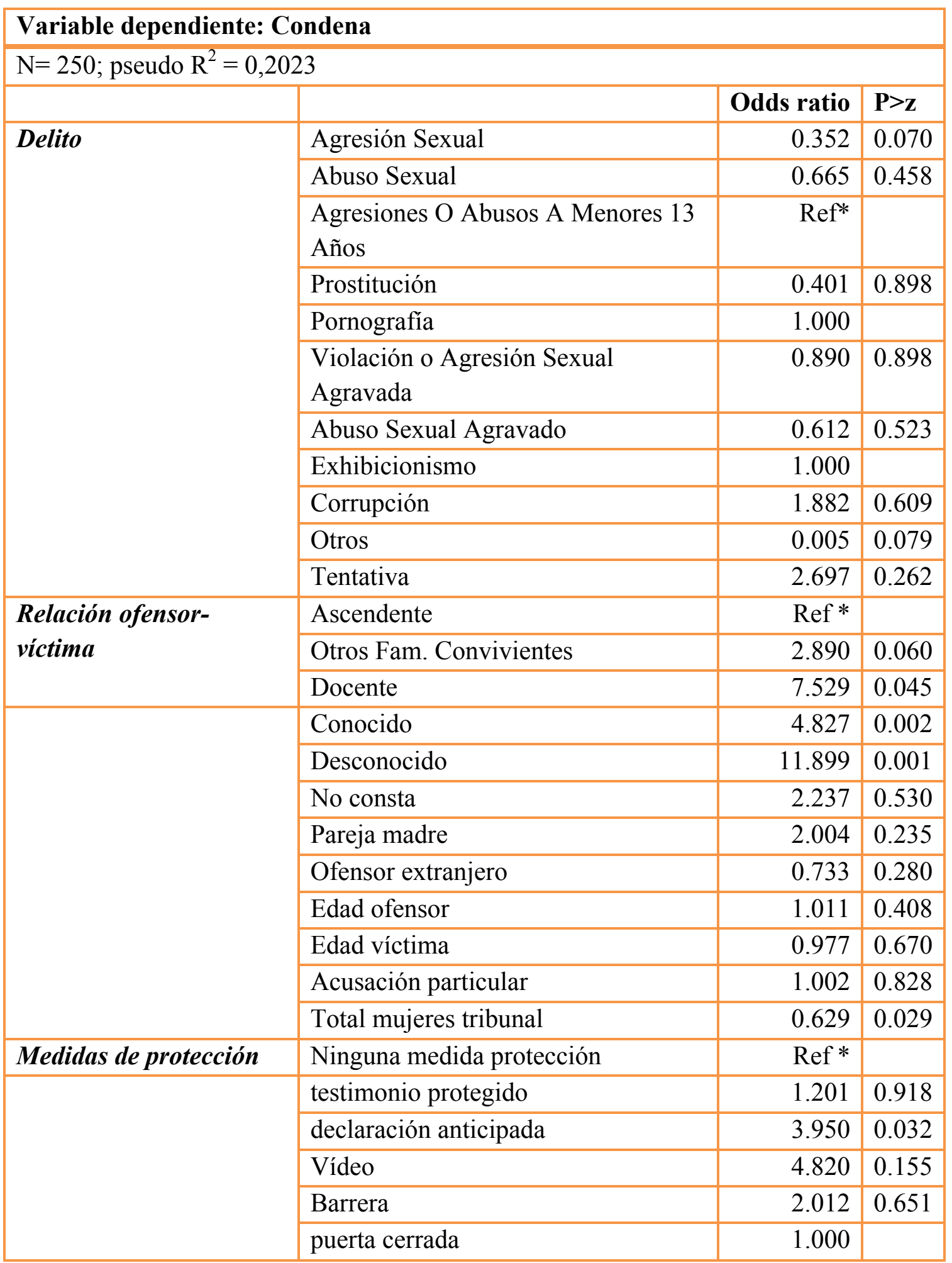




\begin{tabular}{|l|l|r|c|}
\hline \multirow{3}{*}{ Comunidad autónoma } & Nuevo Código Penal & 0.910 & 0.876 \\
\cline { 2 - 4 } & Madrid & Ref * & \\
\cline { 2 - 4 } & Cataluña & 0.263 & 0.026 \\
\cline { 2 - 4 } & Andalucía & 1.159 & 0.776 \\
\cline { 2 - 5 } & Galicia & 1.099 & 0.898 \\
\cline { 2 - 5 } & Constante & 2.586 & 0.351 \\
\hline *Categoría de referencia & \multicolumn{2}{|c}{} \\
\hline
\end{tabular}

Tabla A2. Regresión lineal múltiple

\begin{tabular}{|c|c|c|c|}
\hline \multicolumn{4}{|c|}{ Variable dependiente: Pena de prisión (en meses) } \\
\hline \multicolumn{4}{|l|}{$\mathrm{R}^{2}$ corregida $=0,454, \mathrm{~N}=223$} \\
\hline & & Coef. & $\mathbf{P}>\mathbf{t}$ \\
\hline \multicolumn{4}{|l|}{ Delito } \\
\hline Agresión Sexual & & Ref* & \\
\hline Abuso Sexual & 2 & -9.7 & 0.247 \\
\hline Agresiones O Abusos A Menores 13 & 4 & -2.1 & 0.796 \\
\hline Prostitución & 5 & -25.0 & 0.331 \\
\hline Pornografía & 6 & -35.3 & 0.008 \\
\hline Violación o Agresión Sexual & 7 & 74.6 & 0.000 \\
\hline Abuso Sexual Agravado & 8 & 48.2 & 0.001 \\
\hline Exhibicionismo & 9 & -67.9 & 0.000 \\
\hline Corrupción & 10 & -48.5 & 0.000 \\
\hline Otros & 11 & 70.6 & 0.008 \\
\hline \multicolumn{4}{|l|}{ Circunstancias modificantes } \\
\hline \multicolumn{3}{|c|}{ Ninguna circunstancia o circunstancia agravante y atenuante } & Ref* \\
\hline Agravante, ningún atenuante & 1 & -56.6 & 0.096 \\
\hline Atenuante, ningún agravante & 2 & -10.5 & 0.484 \\
\hline Más de un atenuante o eximente & 3 & -10.3 & 0.610 \\
\hline \multicolumn{4}{|l|}{ Interacción delito * circunstancias } \\
\hline & 12 & 49.1 & 0.292 \\
\hline & 14 & 53.3 & 0.170 \\
\hline & 22 & -5.8 & 0.760 \\
\hline & 24 & -22.8 & 0.279 \\
\hline & 27 & -45.0 & 0.129 \\
\hline & 28 & -24.0 & 0.430 \\
\hline & 32 & -8.4 & 0.747 \\
\hline & 34 & -15.7 & 0.578 \\
\hline & 37 & -83.0 & 0.037 \\
\hline
\end{tabular}




\begin{tabular}{|c|c|c|c|}
\hline & 38 & -42.7 & 0.200 \\
\hline & 39 & 1.4 & 0.972 \\
\hline & Tentativa & -23.3 & 0.004 \\
\hline Relación ofensor-víctim & & & \\
\hline & Ascendente & $\operatorname{Ref} *$ & \\
\hline & Otros fam. convivientes & -20.3 & 0.024 \\
\hline & Docente & -33.1 & 0.019 \\
\hline & Conocido & -18.2 & 0.013 \\
\hline & Desconocido & -23.4 & 0.008 \\
\hline & No consta & -0.6 & 0.966 \\
\hline & Pareja madre & -10.0 & 0.320 \\
\hline & Ofensor extranjero & 1.4 & 0.808 \\
\hline & Edad ofensor & -0.2 & 0.369 \\
\hline & Edad víctima & -1.6 & 0.050 \\
\hline & Conformidad & -20.5 & 0.013 \\
\hline & Acusación particular & -0.5 & 0.927 \\
\hline & Total mujeres tribunal & 2.3 & 0.401 \\
\hline Medidas de protección & Ninguna medida protección & $\operatorname{Ref} *$ & \\
\hline & testimonio protegido & 11.2 & 0.498 \\
\hline & declaración anticipada & -11.0 & 0.170 \\
\hline & Vídeo & 9.0 & 0.605 \\
\hline & Barrera & -9.4 & 0.779 \\
\hline & puerta cerrada & 6.1 & 0.651 \\
\hline & Nuevo Código Penal & 4.8 & 0.552 \\
\hline Comunidad autónoma & Madrid & $\operatorname{Ref} * *$ & \\
\hline & Cataluña & -13.4 & 0.110 \\
\hline & Andalucía & -11.4 & 0.092 \\
\hline & Galicia & -4.6 & 0.612 \\
\hline & Constante & 111.2 & 0.000 \\
\hline *Categoría de referencia & & & \\
\hline
\end{tabular}

Tabla A3. Nuevo código penal y duración de la pena (en meses de prisión)

\begin{tabular}{|c|c|c|c|c|c|}
\hline & Media & Std. Dev. & Freq. & & \\
\hline Código antiguo & 49.179211 & 40.62378 & 279 & & \\
\hline Código Nuevo & 52.451613 & 36.575801 & 31 & & \\
\hline Total & 49.506452 & 40.194249 & 310 & & \\
\hline \multicolumn{6}{|c|}{ Análisis de la Varianza } \\
\hline Source & SS & df & MS & $\mathbf{F}$ & Prob $>$ F \\
\hline Between groups & 298.770251 & 1 & 298.770251 & 0.18 & 0.6679 \\
\hline Within groups & 498914.717 & 308 & 1619.85298 & & \\
\hline Total & 499213.487 & 309 & 1615.57763 & & \\
\hline
\end{tabular}


Tabla A4. Medidas de protección de la víctima y duración de la pena (meses de prisión)

\begin{tabular}{|c|c|c|c|c|c|}
\hline & Media & Std. Dev. & Freq. & & \\
\hline Ninguna Medida & 46.926 & 39.303 & 258 & & \\
\hline Testigo Protegido & 29.143 & 26.479 & 7 & & \\
\hline Declaración Anticip. & 57.286 & 40.272 & 28 & & \\
\hline Vídeo & 69.667 & 54.191 & 6 & & \\
\hline Barrera & 97.500 & 10.247 & 4 & & \\
\hline Puerta Cerrada & 89.143 & 41.342 & 7 & & \\
\hline Total & 49.506 & 40.194 & 310 & & \\
\hline \multicolumn{6}{|c|}{ Análisis De La Varianza } \\
\hline Source & SS & df & MS & $\mathbf{F}$ & Prob $>$ F \\
\hline Between Groups & 28964.1244 & 5 & 5792.82488 & 3.74 & 0.0026 \\
\hline Within Groups & 470249.363 & 304 & 1546.8729 & & \\
\hline Total & 499213.487 & 309 & 1615.57763 & & \\
\hline
\end{tabular}

Tabla A5. Acusación particular y duración de la pena (en meses de prisión)

\begin{tabular}{|l|r|r|r|r|r|}
\hline & Media & Std. Dev. & Freq. & & \\
\hline Sin Acusación Particular & 44.994 & 39.314 & 164 & & \\
\hline Acusació Particular & 54.575 & 40.700 & 146 & & \\
\hline Total & 49.506 & 40.194 & 310 & & \\
\hline Análisis De La Varianza & \multicolumn{5}{|l|}{} \\
\hline Source & SS & df & MS & F & Prob > F \\
\hline Between Groups & 7090.822 & 1 & 7090.822 & 4.44 & 0.036 \\
\hline Within Groups & 492122.665 & 308 & 1597.801 & & \\
\hline Total & 499213.487 & 309 & 1615.578 & & \\
\hline
\end{tabular}


Gráfico A1. Duración de la pena de días-multa impuesta

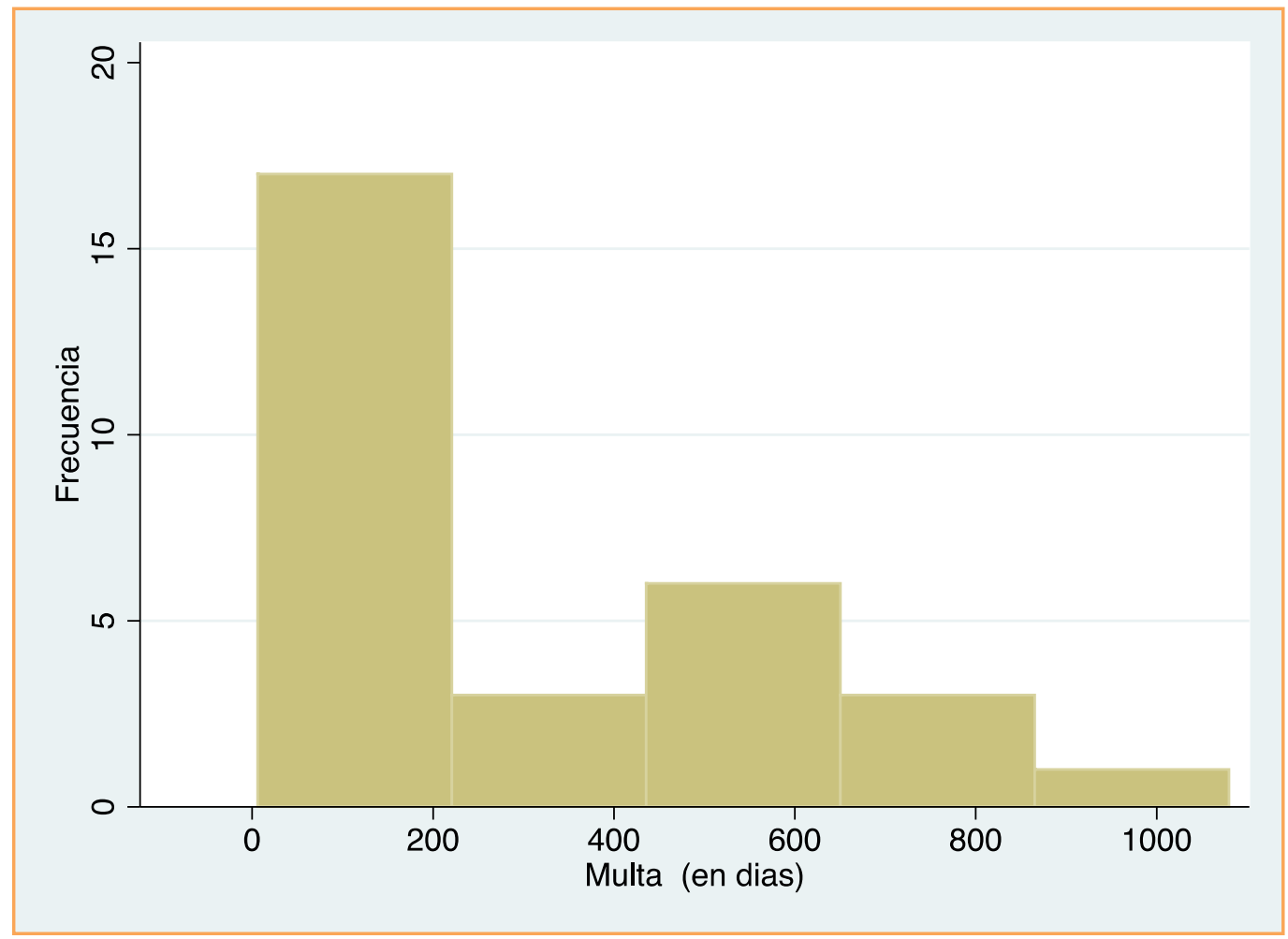

Gráfico A2. Cuantía de la responsabilidad civil derivada del delito

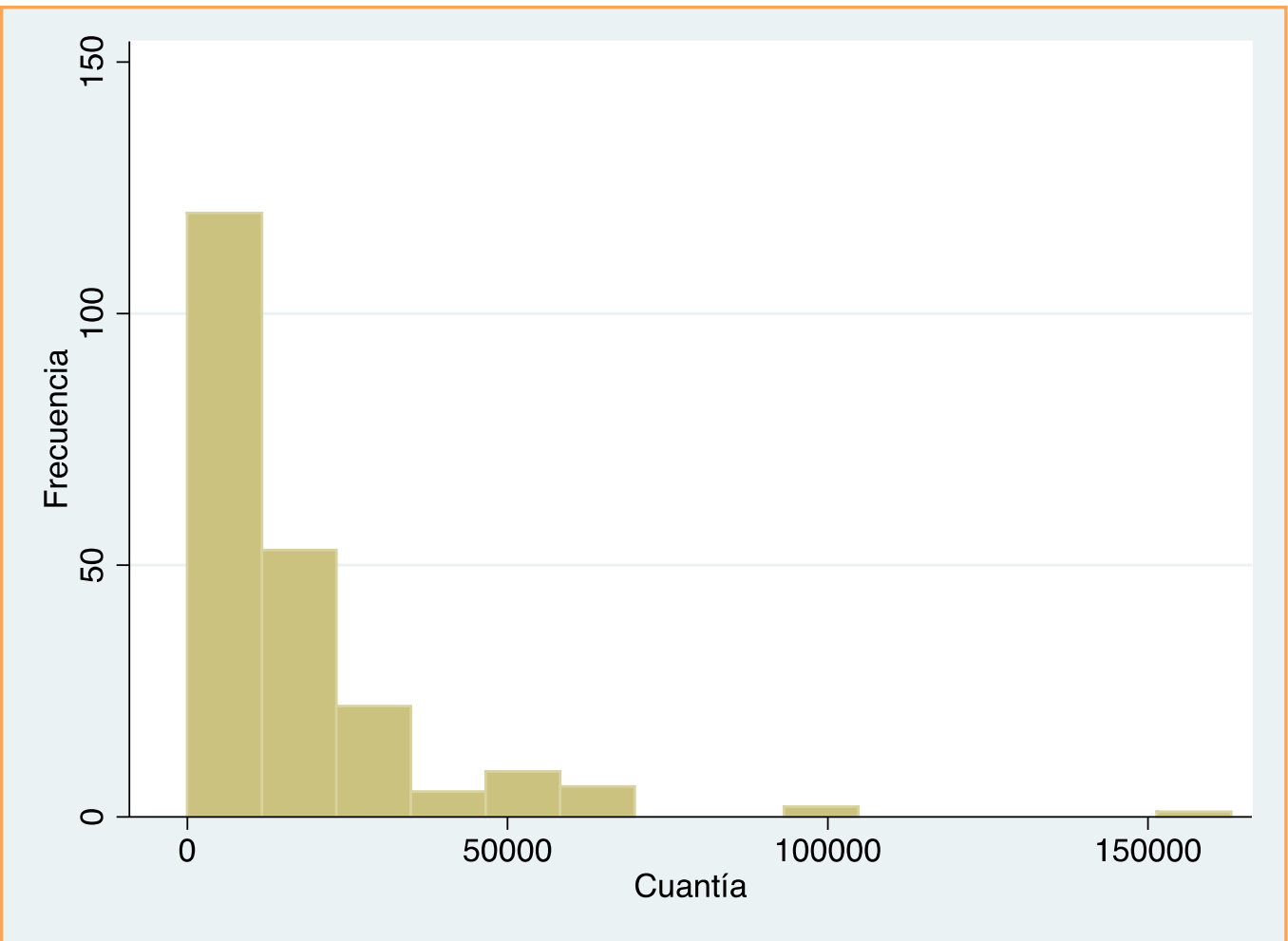

